\title{
O Supremo Tribunal Federal entre o Direito e a Tecnocracia Científica: o caso do amianto
}

\author{
The Supreme Court Between Law and Scientific Technocracy: \\ the asbestos case
}

\author{
Maristela Medina Faria ${ }^{1,2}$ \\ Roberta Camineiro Baggio ${ }^{3}$ \\ ${ }^{1}$ Universidade de Uberaba, Minas Gerais, MG, Brasil \\ ${ }^{2}$ Centro Universitário de Goiatuba, Goiatuba, GO, Brasil \\ ${ }^{3}$ Universidade Federal do Rio Grande do Sul, Porto Alegre, RS, Brasil
}

\begin{abstract}
Resumo: O artigo discute o problema do aumento da utilização de fundamentos científicos em detrimento dos jurídicos nas decisões do Supremo Tribunal Federal (STF) como uma prática própria dos modelos tecnocráticos. Para tanto, analisa-se um complexo conflito de competência constitucional, sobre a regulamentação da utilização do amianto dentro da estrutura federativa brasileira, que permite a identificação dos limites e riscos dessa nova postura cada vez mais comum nos tribunais brasileiros. Trata-se do caso do amianto, um conflito que envolve a Lei federal n. 9.095/95, que regulamenta a questão do uso do amianto no Brasil, e as Leis estaduais que passaram a proibir o uso do mineral. A análise será feita a partir da ADI n. 3.937/SP que demorou dez anos para ser decidida pelo STF.
\end{abstract}

Palavras-chave: Tecnocracia Científica. Conflito Federativo. Caso do Amianto.
Abstract: The article discusses the problem of increasing the use of scientific grounds to the detriment of the legal ones in the decisions of the Federal Supreme Court (STF) as a practice of the technocratic models. In order to do so, it analyzes a complex conflict of constitutional jurisdiction over the regulation of the use of asbestos within the Brazilian federal structure that allows the identification of the limits and risks of this new posture increasingly common in Brazilian courts. This is the case of asbestos, a conflict involving Federal Law n. 9.095/95, which regulates the issue of the use of asbestos in Brazil and state laws that have prohibited the use of the mineral. The analysis will be made from ADI n. 3937/SP, which took ten years to be decided by the STF.

Keywords: Scientific Technocracy. Federal Conflict. Asbestos Case.

Recebido em: 16/02/2019

Revisado em: 18/11/2019

Aprovado em: 10/12/2019 


\section{Introdução}

Diante do complexo quadro de decadência da política e ascensão das instâncias jurisdicionais como um espaço cada vez mais protagonista para a resolução dos conflitos, o presente artigo propõe uma reflexão acerca das consequências da adoção de decisões jurídicas com embasamento técnico-científico que colocam o campo do direito e sua própria normatividade em segundo plano. $\mathrm{O}$ processo de tecnocratização dos modos de governabilidade regionais e globais contribuiu para esvaziar os debates acerca da legitimidade em se projetar decisões finais como indubitavelmente corretas e não necessariamente legítimas pela assunção de dispositivos técnicos indisponíveis aos processos de deliberação.

Como lidar com a situação cada vez mais corriqueira de normas técnicas não submetidas a qualquer processo de decidibilidade ou, ainda, dados científicos que concorrem com a aplicação das normas jurídicas? Como não pensar na legitimidade que envolve decisões que abarcam em suas questões de fundo - mais debates científicos do que debates jurídicos, ignorando questões normativas básicas?

Essas são algumas das questões a serem refletidas nesse artigo a partir da apreciação pelo Supremo Tribunal Federal (STF) da ADI n. 3.937/SP, que chamamos nesse artigo de "caso do amianto".

O cenário do caso analisado é o complexo modelo federativo consagrado na Constituição Federal de 1988, que manteve uma estrutura de repartição de competências exclusivas, privativas e residuais ao lado de um modelo cooperativo de federação com a adoção de competências compartilhadas. A funcionalidade e a articulação dessa nova estrutura federativa nunca foram enfrentadas pelo STF. Os modelos adotados não são excludentes, mas como harmonizá-los nas situações em que o debate sobre a quem pertence uma competência possui mais de uma resposta? Casos complexos, como o do amianto, que perpassam os dois modos de distribuição das competências constitucionais seriam ótimas oportunidades de avançar na definição das estratégias e critérios a serem priorizados em situações em que a União aparece ao mesmo tempo como protagonista de competências exclusivas e privativas e também compartilhando outras 
tantas com os demais entes federados. Ocorre que esse debate tornou-se secundarizado e, em alguns momentos, até mesmo invisibilizado diante dos dados científicos apresentados ao longo do processo de julgamento, o que gerou consequências complicadas no cotidiano da vida social em que a questão tinha alguma incidência.

A estrutura do artigo está dividida em três partes. A primeira desenvolve de forma breve o contexto de ascensão da tecnocracia e como ele atinge as Cortes, na segunda é apresentada a questão jurídica do amianto no Brasil e, por fim, a terceira, em que as decisões são analisadas apresentando a secundarização dos conflitos federativos diante da questão científica e algumas de suas consequências.

\section{O STF no Contexto do Processo de Empoderamento Tecnocrático das Cortes: a complexidade social e a decadência da política}

A ideia de tecnocracia pode ser compreendida como um fenômeno originário das sociedades industriais, consolidada como um modelo inexorável aos processos de busca de níveis elevados de eficiência e padronização do desenvolvimento industrial, que não se limitou no tempo e no espaço a uma determinada etapa inicial desse processo.

Jürgen Habermas interpretou tal fenômeno a partir de um horizonte teórico weberiano concebendo-o como uma nova etapa da dominação burocrática, que já não seria mais racionalizada apenas pelos critérios da divisão do trabalho, mas por competências estruturadas pelo advento das novas tecnologias. No sistema de desenvolvimento capitalista-industrial, o fenômeno da tecnocracia perderia a qualidade de simples fato ou evento para se estabelecer como um modelo inevitável a uma nova dinâmica na seara da própria política, dissolvendo o problema da decisão e tornando-a dependente do rol de técnicas eficientes disponíveis (HABERMAS, 1993, p. 107).

A presença cada vez mais crescente de órgãos técnicos que ganharam espaço de decidibilidade sobre questões políticas relevantes passou a 
ser uma realidade dentro das estruturas dos Estados ocidentais, sobretudo, depois da Segunda Guerra Mundial. O ápice desse processo ocorreu com a crise do Estado Social quando a busca por mais eficiência estatal gerou um deslocamento de poder das instâncias de deliberação política para os órgãos técnicos, capazes de supostamente gerar soluções derivadas de uma expertise concebida como neutra diante da complexidade dos desafios colocados à sociedade, ao mesmo tempo em que, como ressaltou Bobbio, a política passou a ser cada vez mais vista como o "reino da incompetência" (BOBBIO, 1998, p. 1.245).

Contudo, como ressalta Benoit Frydman, as normas técnicas assim como as normas jurídicas são "meios de dirigir os homens e os comportamentos", o que desmascara o discurso de neutralidade da técnica, afinal, sempre serão necessárias decisões acerca desses comportamentos, ou melhor, de quais são os comportamentos desejados e convenientes ao grupo estrito de pessoas que podem tomar as decisões sobre a produção da tecnicidade. E, nesse sentido, a tecnocracia cumpre "[...] uma função essencialmente ideológica, que consiste em mascarar a natureza política das escolhas da qual procedem as normas e os efeitos que elas produzem" (FRYDMAN, 2016, p. 82).

A credibilidade do espaço da política foi substituída paulatinamente pela inevitabilidade demonstrada pelos resultados científicos e estudos técnicos que passaram a ser determinantes para as decisões adotadas, contribuindo, inclusive para a neutralização das responsabilidades políticas. Alessandro Pinzani, ao desenvolver as premissas do discurso tecnocrático, destaca justamente a despersonalização da política, já que as decisões são tomadas como medidas necessárias, derivadas de inevitáveis estudos técnicos, ou seja, uma mera "consequência lógica da aplicação prática de tal saber". Dentro desse horizonte conjuntural, os espaços de decidibilidade política não só perdem sua força legitimadora a priori, como também se estabelece uma zona de conforto aos atores políticos que deixam de se sentir diretamente responsáveis pelas decisões, já que o seu fundamento está sempre vinculado a um estudo técnico-científico, supostamente desinteressado e neutralizado em relação ao campo da política (PINZANE, 2013, p. 160). 
Ao lado das estruturas executivas do Estado, os órgãos que aplicam o direito como os poderes judiciários, não tardaram a ganhar destaque nessa conjuntura de valorização tecnocrática, quer seja pelo crescimento de seu papel técnico potencializado por um Estado altamente produtor de normas, quer seja, pelo aumento das demandas judicializáveis que também ganhou força diante das dificuldades do poder executivo em responder às promessas do Estado Social.

A expansão da utilização das normas técnicas em detrimento das normas jurídicas, nesse contexto, ocorreu de um modo relativamente tranquilo no âmbito dos poderes judiciários, uma vez que aquelas sempre foram aplicadas de forma subsidiária a estas, o que, segundo Benoit Frydman causou certa indiferença por parte dos atores envolvidos quando do aumento da utilização de parâmetros técnicos e científicos que passaram a uma situação de concorrência com as normas jurídicas (FRYDMAN, 2016, p. 87).

No caso brasileiro, ainda que não tenhamos tido um Estado Social como nos países do norte, o empoderamento de nosso poder judiciário se deu, sobretudo, no processo de redemocratização. Passados mais de vinte anos do regime ditatorial o resultado da constituinte desvelou um texto com uma nítida contemplação de mecanismos de empoderamento das estruturas disponíveis e um aceleramento dos processos de judicialização. Por um lado, o rol de direitos estabelecido do modo mais completo já visto em nossa história e, por outro, o reforço a instituições como o Ministério Público e as Defensorias Públicas aptas a efetivar direitos não realizados, assim como uma maior amplitude para a atuação do Supremo Tribunal Federal (STF) com o aumento dos legitimados ativos para propor Ações Diretas de Inconstitucionalidade, bem como pela previsão da Arguição de Descumprimento de Preceito Fundamental (ADPF). A conclusão é a de que, ainda que por motivos históricos diferentes, “[...] os mecanismos jurídicos que se procurou inserir na Constituição Federal de 05.10.1988 alcançam o mesmo movimento concentrador de poder tecnocrático já observado em outros países ocidentais no $2^{\circ}$ pós-guerra" (PÁDUA, 2008, p. 139). 
Nessa nova conjuntura, decisões políticas importantes se deslocaram para o poder judiciário, mais especificamente para o Supremo Tribunal Federal que se caracteriza como uma "comunidade restrita de técnicos do direito"'. O controle do poder político-estatal passou, então, a ser exercido de um modo muito mais intenso por juristas representantes de um pequeno grupo de intérpretes que, em tese, dominam cada vez com mais “competência" a intricada técnica do direito (PÁDUA, 2008, p. 47).

O primeiro problema que decorre desse cenário é a questão cada vez mais debatida pelos teóricos sobre a legitimidade desse movimento de deslocamento tecnocrático do processo deliberativo. Para Claus Offe (1975, p. 70-71), por exemplo, uma das principais críticas a esse modelo tecnocrático é o fato de que este promove um processo de desdemocratização e despolitização, sustentado pela tese de que a tecnocracia é a consequência da "civilização científica" o que, ocasiona inevitavelmente, um "retrocesso e esvaziamento funcional das instituições democráticas".

O segundo problema é o foco do presente artigo e relaciona-se com o aumento de demandas complexas permeadas por diversos conhecimentos científicos alheios ao direito e que têm dominado não só o debate de tais demandas no STF como têm servido, não raras vezes, como embasamento prioritário das decisões dos ministros, ocasionando uma secundarização dos argumentos jurídico-normativos. Essa situação gera uma atuação complexa e contraditória, já que o STF, órgão protagonista do processo de tecnocratização jurídica do país, secundariza esse papel para assumir prioritariamente uma tecnocratização científica distante de sua expertise e competência.

Dessa forma, é possível falar em duas perspectivas tecnocráticas na atuação do STF. Por um lado, esse órgão é composto de "técnicos em direito", que passaram a decidir questões políticas e sociais fundamentais para a sociedade, contribuindo sobremodo para o processo de decadência e deslegitimação da política. Por outro, o STF ao decidir casos que, muitas vezes, são de alta complexidade e envolvem questões de várias áreas da ciência, baseia suas decisões em estudos científicos e dados técnicos disponíveis, originando uma que se denominará aqui de tecnocra-

${ }^{1}$ Este termo é utilizado por João Pedro Chaves Valladares Pádua (2008). 
cia científica. Nessa segunda vertente tecnocrática, os técnicos em direito, ou seja, os ministros do STF, sustentados por conhecimentos científicos e dados especializados, têm deslocado ou secundarizado os argumentos do campo jurídico-normativo para o campo científico, abrindo mão da legitimidade política do processo legislativo que sustenta a produção das normas jurídicas e de suas principais responsabilidades, no mesmo sentido já descrito anteriormente por Pinzani.

O caso a ser trabalhado no presente artigo envolve exatamente uma situação complexa em que os estudos científicos sobre o tema protagonizaram o processo decisório dos ministros, servindo como uma importante fonte para o estudo de um modelo de tecnocracia científica cada vez mais presente nas decisões do STF.

\section{A Questão do Amianto no Brasil e o Contexto de Julgamento da ADI n. 3.937/SP}

Há basicamente dois grupos de amianto ou abesto: os anfibólios e as serpentinas. O primeiro grupo é pouco explorado e sua comercialização já está proibida em grande parte do planeta em virtude dos malefícios que causa à saúde ${ }^{2}$. O segundo grupo tem como principal representante a variedade crisotila, ou ainda, "amianto branco". O Brasil possui em atividade apenas uma mina para exploração desse tipo de amianto, que está localizada em Minaçu, no Estado de Goiás. Essa variedade também causa mal à saúde, mas seguiu sendo utilizada principalmente na construção civil e para o isolamento acústico e térmico. De todo modo, já está banida em 58 países $^{3}$ e, segundo dados da Organização Internacional do Trabalho (OIT), 100.000 (cem mil) trabalhadores morrem por ano em virtude de doenças causadas pela exposição ao asbesto ${ }^{4}$.

\footnotetext{
${ }^{2}$ Todas estas informações foram retiradas do site do Instituto Nacional do Câncer (INCA). Disponível em: http://www1.inca.gov.br/conteudo_view.asp?ID=15. Acesso em: 22 jul. 2015.

${ }^{3}$ Disponível em: http://www.abrea.com.br/07panorama.htm. Acesso em: 22 jul. 2015.

${ }^{4}$ Conferir Resolução sobre o amianto - OIT. Disponível em: http://www.ilo.org/public/ english/protection/safework/health/resolution_on_asbestos.pdf. Acesso em: 23 jul. 2015.
} 


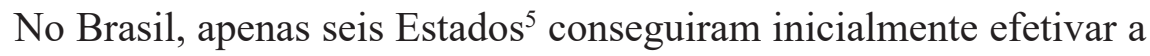
proibição da utilização do amianto branco: Rio de Janeiro, Rio Grande do Sul, Pernambuco, São Paulo, Amazonas e Mato Grosso. À exceção dos dois últimos, todos os outros tiveram a constitucionalidade de suas Leis questionadas junto ao STF.

A Ação Direta de Inconstitucionalidade n. 3.937/SP foi proposta em agosto de 2007 pela Confederação Nacional dos Trabalhadores na Indústria (CNTI) e foi colocada em pauta para ser julgada junto com a ADI n. 3.357/RS, também proposta pela CNTI, em 2004. Em ambas as ADIs alegou-se a inconstitucionalidade das Leis estaduais, tendo em vista que proibiam a utilização de produtos, materiais ou artefatos que possuíssem quaisquer tipos de amianto ou outros minerais que contivessem fibras do abesto na sua composição. A referida proibição ocasionaria um suposto conflito de competência federativa em relação à Lei Federal n. 9.055/95, que permitia a extração, industrialização, utilização e comercialização do amianto da variedade crisotila em todo o território nacional.

Quatro anos antes, em 8 de maio de 2003, o STF teve a oportunidade de manifestar-se pela primeira vez sobre Leis estaduais que vedavam a utilização e comércio do amianto branco, por meio do julgamento das Ações Diretas de Inconstitucionalidade n. 2.396/MS, de relatoria da Ministra Ellen Gracie e a n. 2.656/SP, cujo relator foi o Ministro Maurício Corrêa. Naquela oportunidade, ficou firmado o entendimento no sentido da inconstitucionalidade formal de alguns dos dispositivos das Leis estaduais que proibiam a utilização e comércio do amianto, tendo em vista a invasão de competências exclusivas da União.

Após o julgamento dessas ADIs, foram propostas novas Ações Diretas no STF questionando outras Leis estaduais, que, de alguma forma, restringissem a exploração do amianto branco. As que mais ganharam destaque foram as ADIs n. 3.937/SP e n. 3.357/RS. Primeiramente, porque São Paulo era reincidente na produção de uma Lei proibitiva do uso do amianto. Depois, porque levaram à mudança de entendimento do

\footnotetext{
${ }^{5}$ Alguns municípios também possuem leis proibindo ou restringindo a utilização do amianto da variedade crisotila, entre eles: Barretos, Recife e Natal. Conferir em: http:// www.abrea.com.br/QUADRO\%20ATUAL\%20banimento.htm. Acesso em: 23 jul. 2015.
} 
STF a partir da adoção de argumentos essencialmente fundamentados em questões científicas. Essa guinada interpretativa ocorreu, principalmente, nos debates de apreciação da medida cautelar na ADI n. 3.937/SP, por isso, a sua escolha como objeto principal de análise deste artigo.

Quando da apreciação do pedido liminar para que fosse suspensa a vigência da Lei estadual questionada na ADI n. 3.937/SP, os ministros Marco Aurélio, Menezes Direito e Ellen Gracie votaram pela concessão da liminar seguindo a até então jurisprudência da Corte. Por outro lado, os ministros Ricardo Lewandowski, Eros Grau, Cármem Lúcia, Joaquim Barbosa, Carlos Brito, Celso de Mello e Cezar Peluso votaram pela não concessão. O ministro Gilmar Mendes não participou da sessão de julgamento, portanto, não proferiu seu voto. Dessa forma, por sete votos contrários e três favoráveis, a liminar não foi concedida e a Lei estadual continuou vigente. Foi possível perceber que as informações científicas e os dados técnicos disponibilizados foram determinantes nessa mudança de posição da Corte, como será analisado adiante.

Decidida a liminar no mesmo mês do protocolo da inicial, o STF demoraria cinco anos para iniciar o julgamento conjunto das ADIs n. 3.937/ SP e n. 3.357/RS. Logo após o voto do ministro Ayres Britto (relator da ADI n. 3.357/RS), que decidiu pela improcedência da ação e o voto pela procedência, do ministro Marco Aurélio (relator da ADI n. 3.937/SP), o julgamento foi suspenso tendo sido retomado apenas em agosto de 2017, dez anos depois do início do processo. A tendência de reconhecimento da legitimidade das Leis estaduais que marcou a decisão em relação à medida cautelar foi mantida no julgamento final. O espectro da cientificidade, contudo, não deixou de rondar a decisão principal, demostrando sua força e os desafios postos ao mundo jurídico.

\section{O Conflito Federativo no Caso do Amianto e o Esquecimento da Dimensão Jurídico-Normativa: análise dos argumentos dos ministros}

Em 29 de agosto de 2007, deu-se início ao julgamento do pedido de medida cautelar da ADI n. 3.937/SP, em que a CNTI alegou, como justi- 
ficativa principal de sua legitimidade, os riscos causados pela Lei paulista n. 12.684/07 em relação ao aumento do desemprego de trabalhadores do setor por ela representados. Quanto ao mérito da questão, foram suscitadas três ordens de fatores. A primeira, sobre a afronta à "reserva legal proporcional" e à livre iniciativa dispostas nos incisos II e LIV do artigo $5^{\circ} \mathrm{e}$ no parágrafo único do artigo $170 \mathrm{da} \mathrm{CF}$, uma vez que a proibição ao uso do amianto no mercado é desproporcional diante dos índices científicos de tolerância e isenção de malefícios do produto, gerando um impedimento demasiado oneroso ao desenvolvimento de todas as atividades econômicas vinculadas ao produto.

Em segundo lugar, foram alegados os vícios de inconstitucionalidade, que estariam divididos em duas partes: o de inciativa, já que supostamente a proposição da referida Lei estadual seria competência privativa do poder executivo, de acordo com os incisos II e IV do artigo 84 da CF e não do poder legislativo, como acabou ocorrendo no presente caso. O segundo guarda o cerne da controvérsia jurídica que envolve a questão do amianto no Brasil e é o da usurpação das competências de legislar da União, seja de forma privativa (incisos I, XI e XII do artigo 22), seja de forma geral, quanto à competência concorrente estabelecida no $\S 1^{\circ}$ do artigo 24, sobretudo no que diz respeito às matérias elencadas nos incisos $\mathrm{V}$, VI e XII do mesmo artigo.

$\mathrm{O}$ argumento usado foi o de que, diante da existência da Lei Federal n. 9.095/95, a União estabeleceu seu papel constitucional de regulamentar a matéria tanto privativamente, no que tange à regulamentação do comércio, transporte e recursos minerais (incisos I, XI e XII do artigo 22), como de modo concorrente, estabelecendo normas gerais $\left(\S 1^{\circ}\right.$ do artigo 24) de produção e consumo; proteção do meio ambiente e controle da poluição; e proteção e defesa da saúde (incisos V, VI e XII do art. 24). Ou seja, a Lei federal n. 9.095/95 atenderia ao mesmo tempo às prerrogativas privativas da União, postas no artigo 22, e também cumpriria o papel de norma geral, tal qual a previsão do $\S 1^{\circ}$ do artigo 24 do rol de competências concorrentes entre os entes da federação. Na medida em que os Estados-membros começaram a legislar de modo mais restritivo acerca do uso do amianto do que o disposto na Lei Federal n. 9.095/95, acabaram ocasionando uma insuperável invasão das competências constitucionais 
da União, o que feriria o princípio federativo consagrado no artigo $1^{\circ}$ e no inciso I do $\S 4^{\circ}$ do artigo 60 do texto constitucional.

Por fim, a terceira ordem de alegações dizia respeito a afronta à autoridade do STF, uma vez que a Lei paulista repetiu conteúdo de outra Lei (Lei n. 10.813/01), produzida no próprio Estado de São Paulo, já declarada inconstitucional no julgamento da ADI n. 2.656/SP em 2003.

No voto do relator, o ministro Marco Aurélio, de modo muito sucinto e objetivo, deferiu o pedido de medida cautelar optando, assim, pela suspensão da Lei estadual n. 12.684/07 até a decisão final da ADI, sob o argumento de que a referida Lei causaria embaraços à comercialização dos produtos que contêm amianto, o que acabaria gerando consequências ao comércio interestadual, matéria de competência da União, de acordo com o incido VIII do artigo 22 da CF, tal qual já debatido e enfrentado na ADI n. 2.656-9/SP.

Na sequência dos debates, pronunciou-se o ministro Eros Roberto Grau, decidindo pelo indeferimento do pedido de liminar sob o argumento de que a questão era demasiada complexa para ser esgotada diante da alegação de quebra do princípio da livre iniciativa e que a verdadeira inconstitucionalidade estava na Lei federal que não cumpria um papel adequado de cuidar da saúde da população afrontando o artigo 196 da CF (BRASIL, 2008, p. 74).

Os debates que se seguiram foram no sentido, primeiro, da Corte se defrontar com uma série de laudos científicos controvertidos sobre uma matéria complexa, sustentada por interesses econômicos de grande monta. Depois, sobre a complexidade federativa de matérias tão amplas como o direito à saúde gerarem, na dinâmica federativa das competências compartilhadas, um acúmulo de regulamentações diferentes sobre o mesmo tema.

Acompanharam o relator, a ministra Carmem Lúcia e o ministro Ricardo Lewandowski e, por fim, o ministro Joaquim Barbosa pediu vistas do processo.

O julgamento foi retomado em 4 de junho de 2008 e, antes da apresentação do voto-vista do ministro Joaquim Barbosa, o ministro relator, Marco Aurélio, reforçou seus argumentos discorrendo sobre os efeitos 
práticos da proibição do uso do amianto no Estado de São Paulo, sendo o principal deles, a derrogação da Lei federal no território paulista, o que seria inaceitável sob o ponto de vista da dinâmica federativa. Para o ministro, se os Estados-membros decidissem começar a proibir a comercialização de produtos cancerígenos, como seria o caso do tabaco, haveria um inevitável esvaziamento da competência federativa privativa da União de legislar sobre a organização do comércio (BRASIL, 2008, p. 36).

No voto-vista, o ministro Joaquim Barbosa iniciou sua estratégia argumentativa com um panorama sobre o cenário dos pedidos de inconstitucionalidade a Leis estaduais semelhantes à Lei paulista e ao histórico dos julgamentos já efetuados no STF sobre a temática no ano de 2003, divergindo de todas as conclusões a que a Corte havia chegado até então sobre a matéria. Antes, contudo, de expor sua compreensão sobre as questões envolvidas fez "alguns esclarecimentos de natureza científica" (BRASIL, 2008, p. 39), discorrendo por cerca de três páginas sobre os malefícios do amianto crisotila com base em estudos científicos.

Esses esclarecimentos tornaram-se essenciais para o entendimento da mudança de posição da Corte sobre o tema, porque passaram a protagonizar o debate, colocando em segundo plano os demais aspectos da questão federativa, como será visto mais adiante. Isso ocorreu não só no voto-vista do ministro, mas também na revisão de alguns dos votos que já haviam sido proferidos e nos votos que ainda não haviam sido prolatados.

Logo após a exposição dos argumentos científicos, o ministro Joaquim Barbosa afirmou, ainda, o alto nível de exigência da jurisprudência da Corte quanto às limitações estaduais em relação à livre circulação, que colocariam as decisões do STF fora de padrões de razoabilidade. Seguiu-se, então, uma série de citações jurisprudenciais anteriores ao texto constitucional de 1988 em que os dilemas federativos tratados pela Corte estavam ligados ao debate da divisão de competências exclusivas da União e residuais dos Estados. Isso porque a ideia de uma divisão de competências compartilhadas, aos moldes de um modelo cooperativo de três níveis, seria uma inovação da carta constitucional de 1988. Impossível, portanto, que os debates jurisprudenciais enfrentassem o tema sobre os limites do poder compartilhado de legislar de cada esfera da federação. 
Mesmo demonstrando compreensão sobre a transformação do modelo federativo de 1988, o ministro passou a concentrar-se apenas nas inovações constitucionais sem qualquer menção aos temas de exclusividade da União para legislar que também circundam a problemática do amianto no Brasil e que permaneceram no texto da CF de 1988 - como a questão dos recursos minerais, o transporte e o comércio. $\mathrm{O}$ voto-vista se ateve apenas às competências compartilhadas de proteção à saúde e meio ambiente que, diante do debate científico, converteram-se nas únicas a serem tratadas sobre a matéria.

O ministro afirmou em seu voto estar convencido de que as normas estaduais que regulamentam a questão do amianto e que estavam sendo questionadas no STF não eram inconstitucionais por duas razões. A primeira, ligada à existência da Convenção n. 162 da OIT, ratificada pelo Brasil e que prevê a adoção de legislação protetiva dos trabalhadores expostos ao amianto. Nesse sentido, os Estados-membros estariam cumprindo esse compromisso internacional muito mais do que a União, sobretudo, porque o item 2 do artigo $3^{\circ}$ da referida Convenção prevê que a legislação nacional, adotada com o intuito de prevenir e controlar os riscos da exposição ao amianto “[...] deverá ser submetida a revisão periódica, à luz do desenvolvimento técnico e do aumento do conhecimento científico [...]", o que não estaria sendo feito no âmbito federal, mas estadual com a criação de novas legislações mais protetivas do que a federal.

Quanto à segunda razão pela qual o ministro acreditava na constitucionalidade das leis estaduais era que a Convenção 162 da OIT, uma vez ratificada pelo Brasil, adquirira traços verdadeiros de lei geral e não mais a Lei federal. Desse modo, perderia o sentido o debate entre lei geral e lei específica (BRASIL, 2008, p. 55).

De fato, como já assinalado, em um modelo cooperativo de divisão de competências, a existência pura e simples de uma norma editada pelo âmbito federal, a título de norma geral, não pode e não deve excluir, a priori, o poder de legislar dos Estados-membros de modo suplementar, com vistas ao atendimento de suas peculiaridades regionais. A grande questão é que os motivos do voto se exauriram aqui e a complexidade da questão federativa ficou obscurecida por uma gama de fundamentos cien- 
tíficos que colocou em evidência as matérias de legislação concorrente de proteção à saúde e ao meio ambiente, tornando central apenas o debate da divisão de competências compartilhadas.

Aprofundar, por exemplo, a natureza da norma geral, especificando que a simples existência de norma federal não satisfaz necessariamente a exigência estabelecida como competência concorrente da União no artigo 24 ou, ainda, a possibilidade de que uma norma federal, mesmo considerada geral, pudesse ser suplantada por uma norma internacional teria sido um grande debate sobre a dinâmica jurídica que deve ter uma federação como a brasileira, que adotou um modelo complexo de divisão de competências articulando competências exclusivas e comuns em situações nem sempre fáceis de serem compreendidas dentro de uma estrutura de convivência de três níveis de entes federados.

A força da cientificidade dos argumentos foi tão impactante que todos os votos que se seguiram protagonizaram esse debate. $\mathrm{O}$ ministro Eros Grau, que já havia se manifestado contrariamente ao voto do relator, propôs que o STF extrapolasse o pedido feito na inicial e declarasse inconstitucional a Lei federal, já que os estudos científicos não deixavam dúvidas sobre a prejudicialidade do uso do amianto:

Indago se, em hipóteses como essas, de confronto necessário entre lei estadual e lei federal, a Corte estaria presa ao pedido contido na petição que deflagra a análise da constitucionalidade de determinado tema. Eu penso, Senhor Presidente, que é imprescindível o exame da conformidade da Lei Federal com o texto da Constituição do Brasil. Eu não posso fazer de conta que essa afronta não existe. Desejo, pelo menos do meu ponto de vista afirmar essa inconstitucionalidade, que não posso, em hipótese alguma, fazer de conta que não vejo. Há estudos científicos segundo os quais o uso do amianto é prejudicial à saúde daqueles que manipulam o material. A Lei federal 9505 parece-me violar o art. 196 da Constituição do Brasil. (BRASIL, 2008, p. 61)

Na sequência, a ministra Carmen Lúcia decidiu retificar seu voto porque ao reexaminar a matéria se deu conta de que o direito à saúde é competência concorrente e comum entre os entes da federação, o que no- 
vamente colocaria em evidência apenas as questões relativas à divisão de competências compartilhadas:

Entretanto, reexaminando a matéria agora, verifiquei, conforme os princípios constitucionais, que especialmente alguns direitos, como o direito à saúde, são não apenas da competência concorrente, como realçou o Ministro Eros Grau quanto o Ministro Joaquim Barbosa, mas também de competência comum - é o art. 23, inc. II, da Constituição -, e que, portanto, no exercício dessa competência, aquela norma poderia ter sido editada. Razão pela qual, como eu disse, pedindo vênias ao Ministro Marco Aurélio, eu reajusto o meu voto para acompanhar a divergência, Presidente. (BRASIL, 2008, p. 64-65)

Do mesmo modo, o ministro Ricardo Lewandowski também reviu sua posição e reforçou ainda mais a importância dos estudos científicos para a sua decisão:

O perigo para a saúde da população local ficou evidenciado pelos estudos que o Ministro Joaquim Barbosa apresentou e outros que já foram ventilados aqui ao longo desses debates. O fumus bonis iuris também ficou caracterizado não apenas pela legislação internacional que bane expressamente a produção de bens com essa matéria-prima, o amianto, de outro lado, também, pelos exemplos do direito comparado. Da tribuna veio a notícia de que os países que integram a União Europeia, agora, baniram esse produto de seu mercado. (BRASIL, 2008, p. 67)

O ministro Menezes de Direito decidiu acompanhar o voto do relator, tendo em vista que essa seria uma decisão em sede de medida cautelar e que seria prudente seguir os precedentes da Corte. Por outro lado, o ministro Carlos Britto manteve sua linha inicial de se opor ao voto do relator, reforçando seus argumentos com a invocação da normativa internacional como uma norma supralegal que estaria, portanto, acima da Lei federal e que referendaria a legitimidade dos Estados-membros de legislar sobre o assunto (BRASIL, 2008, p. 76). 
A ministra Ellen Gracie reafirmou sua posição inicial de acompanhar o voto do relator e observou que o espaço de disputa sobre a questão do amianto, considerando que a Lei estadual produzida era de São Paulo, um dos Estados mais populosos e com grande representação no poder legislativo federal, poderia ter sido diretamente o Congresso Nacional no combate à defasada Lei federal (BRASIL, 2008, p. 78). A ministra trouxe suas próprias discordâncias científicas sobre os debates levantados e ressaltou, ainda, que o STF não poderia exercer um papel semelhante ao de uma academia de ciência:

O legislador paulista, no caso, Senhor Presidente, excedeu autorização constitucional voltada para o preenchimento de lacunas, acaso verificadas na legislação federal. A norma paulista obstaculiza completamente a efetividade da norma federal ao impedir comercialização de produtos expressamente autorizados - o Ministro Carlos Britto acaba de nos ler - pela Lei $n^{\circ} 9055$. Evidente, já vou repetir mais uma vez, que não somos academia de ciência. Portanto, não nos cabe definir a nocividade de produtos, mas o que se trata é de um produto completamente diferente daquele radicalmente proibido, inclusive na Convenção da OIT, que é o anfibólio. (BRASIL, 2008, p. 79)

Por fim, o voto do ministro Cezar Peluso acompanhou os votos divergentes dos ministros Joaquim Barbosa e Eros Grau, demonstrando haver compreendido muito bem que o debate deixou de ser sobre repartição das competências e, em concordância com o abandono do tema federativo, reforçou os argumentos do protagonismo científico:

A mim me parece - e, nesse ponto, fiquei, realmente, impressionado com os fundamentos dos votos dos eminentes Ministros Joaquim Barbosa e Eros Grau - que o problema pode ser posto em outro plano e em outro âmbito que não o de conflito de competência e, por isso, não se trata de precedente que ponha em risco a separação das competências. Parece-me que - e acompanho aqui, portanto, o raciocínio do eminente Ministro Eros Grau -, também por todas as razões já expostas e adiantadas pelo Ministro Joaquim Barbosa, e diante, até, dos termos da convenção internacional a que 
o Brasil aderiu, é reconhecido o perigo ou nocividade que o uso do amianto, nessa modalidade, representa para a saúde. (BRASIL, 2008, p. 139)

Com exceção desse último voto do ministro Cezar Peluso que afastou quase que por completo o debate da competência federativa, em geral, pode-se depreender que o foco do debate, sobretudo após a apresentação do voto-vista do ministro Joaquim Barbosa, passou a ser a possibilidade de os Estados-membros legislarem de modo mais restritivo do que a União em matéria de proteção do meio ambiente e da saúde sem que isso significasse necessariamente uma afronta ao poder da esfera federal de estabelecer normas gerais. Ou ainda, a possibilidade de se questionar se a regulamentação de determinada matéria compartilhada foi de fato construída como uma norma geral que não limitaria o poder dos Estados-membros de legislar para atender às suas peculiaridades.

De fato, essas questões representam boa parte do conjunto de inovações e, ao mesmo tempo desafios do modelo cooperativo de federação da CF de 1988, ao lado do já consagrado modelo de competências exclusivas e residuais. O problema nesse caso específico do amianto, não é debater a legitimidade do poder de legislar dos Estados-membros em matéria compartilhada com a União, como é o caso da proteção ao meio ambiente e à saúde, para atender aos "interesses da comunidade" (BRASIL, 2008, p. 55), mas é ignorar todas as consequências que a mesma Lei estadual poderia ter trazido e trouxe quanto a questões básicas de transporte e comércio que só poderiam ser reguladas pela União por um motivo singelo: dizem respeito aos interesses comuns dos entes federativos, perpassando a todos indistintamente e, por isso, precisam ser regulados de modo uniforme e equitativo com o fim de garantir uma dinâmica minimamente ordenada e equânime entre os membros da federação.

O grande desafio que a questão do amianto trouxe ao modelo federativo brasileiro foi o de justamente concatenar a prioridade de um tema como a garantia da proteção da saúde e do meio ambiente com a manutenção de uma dinâmica social, política e econômica de articulação entre os entes da federação. Contudo, esse debate tornou-se totalmente secundarizado no julgamento do STF em prol da lógica da tecnocracia científi- 
ca prolatada como figura principal no voto do ministro Joaquim Barbosa e à qual a maioria se rendeu, seja pela forma como interpretaram a Convenção 162 da OIT, seja pelo modo como ignoraram as possíveis consequências da legislação estadual em análise para o funcionamento dos interesses comuns à federação brasileira.

$\mathrm{O}$ resultado não poderia ter sido outro. Alguns anos mais tarde, em setembro de 2011 a Corte teve que enfrentar mais um pedido de medida cautelar na ADPF n. 234, impetrada pela Associação Nacional do Transporte de Cargas e Logística em que muitas das ausências do debate feito na decisão sobre o pedido liminar da ADI n. 3.937/RS voltaram à tona como problemas práticos de primeira ordem para serem resolvidos. A controvérsia posta aqui era a de que, diante da confirmação de validade da norma estadual, os fiscais do trabalho passaram a impedir o transporte de produtos com amianto nas rodovias de São Paulo, inclusive nas federais. Considerando que o maior produtor de amianto é o Estado de Goiás, sempre que este vendia seu produto a um Estado da região sul ou até mesmo para o exterior, era imprescindível que o produto pudesse entrar no Estado para ser escoado, seja porque a malha viária nacional não oferece alternativa que não a de passar por São Paulo para chegar ao sul, seja porque o principal porto exportador do país está localizado na cidade de Santos, no Estado de São Paulo.

Diante do já anunciado, mas não enfrentado problema durante a votação da liminar na ADI n. 3.937/RS, a Corte voltou a tratar do tema decidindo que, de fato, o transporte interestadual era matéria de competência exclusiva da União e que, portanto, os produtos derivados do amianto poderiam adentrar o espaço estadual para seguirem sua destinação final. Não sem recordar sua tentativa de debater o assunto durante a ocasião da apreciação da medida cautelar da ADI n. 3.937/RS, o ministro Marco Aurélio, também relator da ADPF n. 234, argumentou a obviedade totalmente ignorada anteriormente: "Os serviços públicos que, igualmente, funcionam em todo o território devem ficar a cargo da União" (BRASIL, 2011, p. 11).

$\mathrm{O}$ voto do relator venceu por maioria, contando com a divergência dos ministros Carlos Britto, Celso de Mello e Cezar Peluso. Após a deci- 
são sobre a liminar na ADI n. 3.937/RS, o relator, ministro Marco Aurélio decidiu pelo chamamento de uma audiência pública, que aconteceu em 24 de agosto de 2012 e que se configurou como um espaço de reforço do debate tecnocrático-científico.

Em novembro de 2016 entrou na pauta do STF, a ADPF n. 109, de relatoria do ministro Edson Fachin, cujo objeto era a contestação da Lei municipal n. 13.113/01, que proibia o uso do amianto na cidade de São Paulo. Na mesma ocasião, entraram em pauta todas as ações ajuizadas pela Confederação Nacional dos Trabalhadores da Indústria sobre o mesmo tema, entre elas a ADI n. 3.937/RS. Na ocasião, o ministro Dias Toffoli pediu vistas e recolocou o processo em pauta em 24 de agosto de 2017, quando se deu a decisão final, dez anos depois do início de sua apreciação no STF.

O voto-vista, que venceu por maioria, defendeu a improcedência do pedido feito na inicial e foi dividido em duas grandes partes. Uma primeira intitulada "Análise sob a perspectiva da competência legislativa" e a segunda, "O atual estágio do debate público e científico acerca do amianto crisotila (asbesto branco) e o processo de inconstitucionalidade do artigo $2^{\circ}$ da Lei Federal n. 9.095/1995".

Mesmo dedicando uma parte inteira para o debate da competência federativa, o ministro não enfrentou a questão das competências exclusivas da União, tampouco a relação de articulação que deveria existir entre as duas formas de repartição de competências da $\mathrm{CF} / 88$, dedicando-se exclusivamente ao debate do papel de legislar de cada ente federativo no sistema cooperativo de repartição de competências. Ainda que para a construção do raciocínio lógico desenvolvido pelo ministro bastasse o esclarecimento sobre as competências concorrentes, o argumento principal utilizado pelo ministro Marco Aurélio, relator do processo, foi o da existência de competências legislativas privativas da União sobre o tema do amianto, em especial, trânsito e transporte, jazidas e comércio interestadual. Contudo, tais argumentos não foram considerados.

O protagonismo da questão técnico-científica na definição do voto-vista foi uma constante e serviu como base principal para a resolução da incompatibilidade entre as normas estaduais e federal. O raciocínio de- 
senvolvido pelo ministro foi o de que "[...] a Lei n. 9.055/95 passou por um processo de inconstitucionalização, em razão da alteração no substrato fático do presente caso" (BRASIL, 2017, p. 15) e por isso, foi declarada incidentalmente inconstitucional. Como, de acordo com o $\S 3^{\circ}$ do artigo 24 da CF/88, na ausência de lei federal os Estados-membros e DF têm a competência legislativa plena para legislar, as Leis estaduais debatidas, poderiam ser consideradas constitucionais diante do vácuo legislativo estabelecido pelo próprio voto quando do reconhecimento da inconstitucionalidade do artigo $2^{\circ}$ da Lei federal.

O processo de inconstitucionalização estaria vinculado, na opinião do ministro, à segurança científica que o tema alcançou nos últimos tempos:

[...] deve-se considerar o avanço do conhecimento científico acerca dos efeitos do amianto à saúde e ao meio ambiente, havendo, quanto a esse aspecto, repita-se, consenso científico dos órgãos de proteção à saúde acerca da natureza altamente cancerígena do referido mineral, o qual aponta para a impossibilidade de seu uso seguro. (BRASIL, 2017, p. 16, grifos do original)

O convencimento do ministro quanto aos perigos do amianto ocorreu em decorrência da audiência pública ocorrida em 2012. De acordo com Dias Toffoli,

[...] a realização da referida audiência pública elevou o debate sobre a questão no Tribunal a outro patamar. Com efeito, a abordagem do tema sob diferentes perspectivas desvelou uma nova ordem de fatores a serem considerados no julgamento deste caso. Dentre eles, sobressai o fato de estarmos diante de um tema de natureza técnico-científica, cuja compreensão e tratamento jurídico-normativo dependem do estágio do desenvolvimento científico em que se encontre o observador. (BRASIL, 2017, p. 15 , grifos do original)

Ao atrelar o tratamento jurídico-normativo ao desenvolvimento científico da questão não restou mais lugar para o debate em outros ter- 
mos que não os parametrizados pela ciência. Toda possibilidade de desenvolvimento de argumentos normativos acabou suplantada pela inexorabilidade científica sobre como o amianto se comporta no meio ambiente de forma maléfica, comprovado pelos índices de mortalidade que chegam a $80 \%$ em um ano após a descoberta do diagnóstico de câncer (BRASIL, 2017, p. 17).

Sob o ponto de vista imediato acerca do resultado prático-material da decisão, poderia se pensar, a priori, que a manutenção da constitucionalidade das leis estaduais que possibilitam maior proteção tanto ao meio ambiente quanto aos seres humanos foi um avanço no sentido da superação da tendência centralista do federalismo brasileiro. Contudo, a análise mais detida do processo nos indica que a afirmação dessa proteção com base apenas nas questões científicas e não nas questões científicas como mais um elemento a ser considerado dentro de quadro normativo da dinâmica federativa da Constituição, não representa necessariamente um avanço.

Ao contrário do que pode parecer, a decisão do ministro Dias Toffoli reforça a tendência centralista das decisões do STF em matéria federativa no âmbito da jurisdição constitucional (TOMIO; ROBL FILHO; KANAYAMA, 2015, p. 89-95). Isso porque o argumento sobre a manutenção da constitucionalidade das leis estaduais nada tem a ver com o reconhecimento da legitimidade legislativa dos entes subnacionais regulamentarem de forma mais protetiva as matérias concorrentes a partir de suas demandas regionais. Essa tese é afastada peremptoriamente pelo ministro que admite a possibilidade de manutenção das legislações subnacionais apenas diante da ausência de norma geral federal diante da declaração incidental da inconstitucionalidade do artigo $2^{\circ}$ da Lei n. 9.095/95:

Assim, se a lei federal admite, de modo restrito, o uso do amianto, em tese, a lei estadual ou municipal não poderia proibi-lo totalmente, pois, desse modo, atuaria de forma contrária à prescrição da norma geral federal. Nesse caso, não temos norma suplementar, mas norma contrária/substitutiva à lei geral, em detrimento da competência legislativa da União. [...] No entanto, pelos fundamentos que serão expostos a seguir, entendo que o art. $2^{\circ}$ da Lei federal 
$n^{\circ} 9.055 / 1995$ passou por um processo de inconstitucionalização e, no momento atual, não mais se compatibiliza com a Constituição de 1988, razão pela qual os estados passaram a ter competência legislativa plena sobre a matéria até que sobrevenha eventual nova legislação federal, nos termos do art. $24, \S \S 3^{\circ}$ e $4^{\circ}$, da CF/88. (BRASIL, 2017, p. 11, grifos do original)

No presente caso, a inconstitucionalidade incidental da Lei federal acabou servindo como um reforço à lógica centralista de que normas gerais jamais podem ser contrariadas por leis regionais. Seguindo esse raciocínio, no momento em que uma nova lei federal for aprovada, ab initio, as leis estaduais serão suspensas nos termos em que contrariarem o novo texto legal, afinal, o ministro não vê " [...] espaço constitucional para a tese de que, em matéria de competência legislativa concorrente - inclusive em relação à proteção do consumidor, da saúde e do meio ambiente -, as normas estaduais e municipais devam prevalecer sobre a norma geral federal caso elas sejam mais protetivas e estejam em oposição à disciplina federal".

Na prática, o não reconhecimento dessa possibilidade de que normas estaduais contrariem norma nacional naquilo que diga respeito às suas peculiaridades regionalizadas gera uma hierarquização entre as normas da federação, ainda que o ministro demonstre clareza sobre as regras de convivência em um modelo cooperativo de federação:

No modelo vertical de repartição de competências (corporificada na competência concorrente), há atividade conjunta e complementar dos entes, sem implicar hierarquia entre atos normativos de cada ente federado, mas campos de atribuição distintos, predefinidos constitucionalmente. (BRASIL, 2017, p. 7, grifos do original)

Sob esse ângulo, o voto-vista retrocede ainda mais em relação aos debates feitos na ocasião da decisão liminar, uma vez que naquele momento o foco das discussões se concentrou na dinâmica do modelo cooperativo e na compreensão de que a Lei paulista poderia contrariar a federal porque se tratava de aumentar a proteção de seus cidadãos. A crítica 
feita nesse artigo a essa decisão é a de que os ministros não se dedicaram a pensar como esse quadro cooperativo, totalmente determinado à época pelo debate cientificista, poderia subsistir diante das prerrogativas privativas da União sobre o tema, gerando a posteriori a zona de tensão com a questão do comércio interestadual dirimida na ADPF n. 234.

No voto-vista do ministro Dias Toffoli, o cientificismo seguiu sendo o protagonista do fundamento da decisão, possibilitando a manutenção da tendência centralista de não reconhecer a autonomia regional para legislar contrariamente à União quando as peculiaridades regionais se impõem e seguiu ignorando os desafios de articulação entre os modelos federativos de repartição de competências exclusivas e cooperativas.

\section{Conclusão}

No caso do amianto, as questões basicamente de exploração de jazidas, comércio e transporte interestadual são de competência exclusiva da União, contudo, os malefícios à saúde da utilização desse minério na construção civil e os danos ambientais por ele causados encontram-se na seara das competências compartilhadas. Como compatibilizar essas perspectivas em termos de dinâmica federativa?

Muito pouco se tem feito acerca do aprofundamento desse debate e o STF, como um espaço privilegiado de apreciação de questões desse tipo não tem conseguido contribuir a contento. A questão do amianto foi tratada, em um primeiro momento, como se a única possibilidade de solução do conflito federativo fosse escolher entre debater as competências exclusivas, invocadas pelo relator, ministro Marco Aurélio, ou embarcar na tese do voto divergente, apresentado pelo ministro Joaquim Barbosa, que a partir de dados científicos direcionou o problema para ser uma questão só de competências compartilhadas, quando o enfrentamento das duas questões importava para a manutenção do equilíbrio federativo. Em um segundo momento, quando a decisão final foi tomada a partir do voto-vista do ministro Dias Toffoli, a questão seguiu protagonizando a cientificidade da situação também se limitando ao debate das competências compartilhadas. 
O modo como o debate técnico-científico concorreu com a questão jurídica principal - a federação - de modo que esta ficasse secundarizada ao longo de todo o julgamento é perplexante. A partir de uma "escala" valorativa sobre a importância dos resultados científicos essa questão acabou por tornar-se hierarquicamente prioritária em muitos dos votos analisados, a ponto do debate federativo sobre as competências exclusivas não ter sido praticamente enfrentado por nenhum ministro que aderiu ao voto divergente, tanto na decisão da medida cautelar, quanto na decisão final. Não há nenhuma dúvida sobre a importância em se debater os malefícios da utilização do amianto, tanto para a saúde humana como para o meio ambiente, afinal, essas também são questões próprias de normatização jurídica.

O desafio, nesse caso, é perceber que, de fato, como destacou Benoit Frydman, os modos de normatização técnico-científicos cada vez mais perdem seu caráter subsidiário para tornarem-se concorrentes da normatização jurídica. A naturalização desse fenômeno se dá porque nos moldes de um padrão tecnocrático de tomada de decisões a técnica se resguarda pela sua suposta neutralidade e inevitabilidade, uma vez que seus resultados são divulgados como modos de melhoria da vida humana.

Assim como as normas jurídicas estão atreladas a um resultado decisório de agentes que possuem interesses e um local de fala bem determinado, os resultados de estudos técnico-científicos que servem de base para a produção das normas técnicas também estão. Contudo, as primeiras são respaldadas pela legitimidade de processos de decidibilidade próprio dos Estados de Direito, enquanto as segundas estão completamente fora desse âmbito, sendo simplesmente fruto de conveniências pontuais, privadas e até mesmo aleatórias em relação às demandas de interesse público. Negligenciar a necessidade de enfrentar as questões de legitimidade do uso da técnica ou da ciência como técnica não representa um perigo apenas aos pressupostos básicos da política, como demonstram os enfoques mais comuns sobre a temática até o momento, mas à própria normatividade do direito. 


\section{Referências}

BOBBIO, Norberto; MATTEUCCI, Nicola; PASQUINO, Gianfranco. Dicionário de política I. Brasília: Universidade de Brasília, 1998. BRASIL. Instituto Nacional de Câncer (INCA). [2015]. Disponível em: http://www1.inca.gov.br/conteudo_view.asp?ID=15. Acesso em: 20 maio 2015.

BRASIL. Supremo Tribunal Federal. Medida cautelar na Ação Direta de Inconstitucionalidade n. 3.937/SP. Confederação Nacional dos Trabalhadores na Indústria e Governador do Estado de São Paulo e Assembleia Legislativa do Estado de São Paulo. Relator: Min. Marco Aurélio. [2008]. Disponível em: http://redir.stf.jus.br/paginadorpub/ paginador.jsp?docTP=AC\&docID=553763. Acesso em: $1^{\circ}$ jun. 2017.

BRASIL. Supremo Tribunal Federal. Medida Cautelar na Arguição de Descumprimento de Preceito Fundamental n. 234/ Distrito Federal. Associação Nacional do Transporte de Cargas e Logística. e Governador do Estado de São Paulo e Assembleia Legislativa do Estado de São Paulo. Relator: Min. Marco Aurélio. [2011]. Disponível em: http://redir. stf.jus.br/paginadorpub/paginador.jsp?docTP=TP\&docID=1694638. Acesso em: 12 jun. 2017.

BRASIL. Supremo Tribunal Federal. Ação Direta de Inconstitucionalidade n. 3.937/SP. Voto-vista. Ministro Dias Toffoli. Confederação Nacional dos Trabalhadores na Indústria e Governador do Estado de São Paulo e Assembleia Legislativa do Estado de São Paulo. Relator: Min. Marco Aurélio. [2017]. Disponível em: http://www.stf.jus. br/arquivo/cms/noticiaNoticiaStf/anexo/votoDTamianto.pdf. Acesso em: 16 dez. 2017.

FRYDMAN, Benoit. O fim do Estado de Direito: governar por standards e indicadores. Porto Alegre: Livraria do Advogado, 2016.

HABERMAS, Jürgen. Técnica e ciência como "ideologia". Lisboa: Edições 70, 1993. 
MARTINS, Carlos Estevan. Tecnocracia ou tecnoassessoria? Revista de Administração de Empresa, São Paulo, v. 10 n. 3, p. 39-60, julset., 1970. Disponível em: http://www.scielo.br/scielo.php?pid=S0034$75901970000300002 \&$ script=sci_arttext. Acesso em: 25 nov. 2015.

OFFE, Claus. O dilema político da tecnocracia. In: OFFE, Claus.

Tecnocracia e Ideologia. Rio de Janeiro: Biblioteca Tempo Universitário, 1975. p. 70-84.

PÁDUA, João Pedro Chaves Valladares. A tecnocracia jurídica: a comunidade de intérpretes do direito e o enfraquecimento democrático. 2008. 234p. Dissertação (Mestrado) - Pontifícia Universidade Católica do Rio de Janeiro, 2008.

PINZANE, Alessandro. Democracia versus tecnocracia: apatia e participação em sociedades complexas. Revista Lua Nova, São Paulo, n. 89, p. 135-168, 2013.

TOMIO, Fabrício Ricardo de Lima; ROBL FILHO, Ilton Norberto; KANAYAMA, Rodrigo Luis. Constitucionalismo estadual e controle abstrato e concentrado de constitucionalidade nos tribunais de justiça: efeitos das ações de inconstitucionalidade (ADI) estaduais na federação brasileira. Revista de Direito Brasileira, Florianópolis, ano 5, v. 12, p. 87-110, 2015.

\section{Maristela Medina Faria}

E-mail:mmedinafaria@gmail.com

Docente do curso de Direito na Universidade de Uberaba e no Centro Universitário de Goiatuba (UniCerrado). Mestre em Direito Público pela Universidade Federal de Uberlândia.

Endereço profissional: Av. Marcos de Freitas Costa, n. 1.041, Bairro Daniel Fonseca, Uberlândia, MG. CEP: 38400-328. 


\section{Roberta Camineiro Baggio}

E-mail: roberta.baggio@ufrgs.br

https://orcid.org/0000-0003-4907-6105

Professora Associada dos cursos de Graduação e Pós-Graduação da Faculdade de Direito da Universidade Federal do Rio Grande do Sul (UFRGS).

Endereço profissional: Av. João Pessoa, n. 80, Centro Histórico, Porto Alegre, RS. CEP: 90040-000. 